\title{
RITUAIS DE INICIAÇÃO E RELAÇÕES COM A NATUREZA ENTRE OS MBYA-GUARANI
}

Marilyn Cebolla Badie

Os primeiros indícios de que os ritos de puberdade, mantidos zelosamente ocultos aos olhos dos brancos, ainda eram realizados entre os Mbya, chegaram a mim por acaso a partir da mudança no comportamento das moças. Em certas ocasiões, algumas delas, que tinha visto na minha última estadia em campo com seus cabelos compridos e comportamentos ainda de crianças, segundo as regras sociais mbya, mostraram mudanças radicais no momento de meu retorno à aldeia alguns meses depois. Encontrei-as não apenas com o cabelo cortado rente ou quase raspado em alguns casos, mas também esquivas e com atitudes distintas; pareciam mais sérias e circunspectas. Algumas, tendo ainda o cabelo curto, estavam morando com algum adolescente e já nos primeiros meses da gravidez.

Elas já não vinham me receber com abraços e expressões de alegria quando chegava ao local, quase não falavam comigo e, quando eu queria tirar uma fotografia delas, desviavam o olhar para o chão. Essa mudança no comportamento levou-me a perguntar o que tinha acontecido e, depois de muitas delongas, a resposta que me deram os indígenas foi que durante o tempo em que eu havia me ausentado as meninas "estiveram iñengue" e no meu retorno já "estavam em kuña tai", como se tivessem passado por um processo de transformação. O que esta explicação significava era que haviam atingido a maturidade sexual e seu novo status tinha sido sancionado por meio do ritual de iniciação.

A designação iñengue refere-se ao intervalo de tempo entre a menarca e a finalização da segunda ou terceira menstruação, no qual as meninas são submetidas a um período de reclusão, depois continuam as restrições alimentares e os cuidados, até que a conclusão desta etapa seja apontada com a expressão iñengue páma. Uma mulher é iñengue somente durante alguns meses na sua vida, porém esse tempo parece ser um dos mais importantes do ciclo vital. Este termo tem confundido alguns autores em função da partícula ñe que, neste caso, não está relacionada com ñe'ê, "palavra-alma", 
que significa "fluir" ou "se derramar". Deste modo, considero apropriada a tradução que faz Cadogan (1992a:139), que também registra o nome como iêngue e que propõe como significado "aquela de quem saiu ou fluiu (a menstruação)". As mulheres consultadas ${ }^{1}$ explicaram que faz referência a "que flui ou derrama-se aquilo que foi dela", em clara referência ao sangue menstrual.

No caso de ñe'ênguchu, o assunto resolve-se com mais facilidade, porque se refere ao tom grave que adquire a voz dos rapazes; significa literalmente "voz grande". São denominados ñe'ênguchu quando começam a ter mudanças na voz e o período prolonga-se até que o varão adquire o tom definitivo, então se fala: ñe'ênguchu páma, marcando o final do período de iniciação. Tinha antes escutado falar sobre as iñengue e os ñe'ênguchu em relação ao modo de agir dos espíritos da floresta. Quando os Mbya falavam a respeito dessas entidades, indefectivelmente mencionavam as meninas e os meninos que se encontravam na etapa da puberdade como os mais vulneráveis aos seus ataques.

Mesmo que os dados para esta pesquisa tenham sido coletados de maneira fragmentada desde o ano de 1997 aproximadamente, no percurso de distintos estudos realizados com os $\mathrm{Mbya}^{2}$ que moram na província de Misiones, Argentina, o maior estoque de informação foi obtido durante a pesquisa etnográfica para minha tese doutoral (Cebolla Badie 2013), na qual indaguei sobre a relação natureza-cultura nessa etnia.

Do mesmo modo, entre 2009 e 2011 fiz pesquisa de campo de maneira específica sobre os ritos de puberdade, entrevistando principalmente anciãos de ambos os sexos, para os quais fui encaminhada pelos mburuvicha, ou "mais velhos" das aldeias, que argumentaram que muitas práticas dos rituais já não eram mais realizadas devido às mudanças no mbya reko ou "sistema de vida mbya", a partir do contato permanente com a sociedade nacional. A relação de amizade mantida ao longo dos anos com as pessoas das comunidades e o conhecimento obtido em pesquisas precedentes permitiram-me indagar sobre os temas considerados "delicados" pelos Mbya, e que usualmente são evitados nas conversas com as pessoas não indígenas. De outro lado, as minhas estadias nos locais possibilitaram que eu observasse e acompanhasse nas suas tarefas cotidianas aquelas moças que se encontravam na etapa posterior à reclusão. A pesquisa foi feita em aldeias de zonas muito diferentes de Misiones: em Jejy e Yryapy (Departamento Guarani), Takuapi e Ita Poty (Departamento Libertador General San Martín) e Fortín Mbororé (Departamento Iguazú). Este artigo constitui uma apresentação sucinta dos dados coletados e uma análise preliminar dos mesmos. 


\section{Iñengue}

A principal característica do rito de iniciação das meninas é a reclusão a que são submetidas e que, na sua forma mais completa, hoje em dia somente se dá nas comunidades que ficam afastadas das populações brancas. Quando uma moça avisa que está menstruando pela primeira vez, a avó ou a mãe lhe corta os cabelos e a leva até o opy, ou casa de cerimônias. Ali é especialmente preparado um lugar em que permanecerá durante o tempo de reclusão, compartilhando em algumas ocasiões o espaço com outra menina que esteja na mesma situação.

As sólidas construções mbya, de tetos de canas cortadas e paredes de troncos e canas entretecidas cobertas de barro, caracterizam-se por não ter janelas, sendo a única abertura — fonte de iluminação — uma porta de tamanho reduzido. Desse modo, são frescas no verão e quentes no inverno, mas sempre escuras. A iñengue deve permanecer no fundo do opy, no setor menos iluminado, na penumbra. Os Mbya referem-se ao começo do período de isolamento como oguapy ma, "sentou-se", já que a moça deve ficar sentada ou deitada, sem se mexer, enquanto permanece dentro do opy.

Esse ritual de iniciação repete-se com as mesmas características entre etnias Guarani muito próximas entre si, como os Ñandéva ${ }^{3}$ e os Kaiowá ${ }^{4}$ (Schaden 1974), os Ache-guayakí (Mayntzhusen 2009) e os Chiriguanos ${ }^{5}$ (Hirsch 2008). A reclusão é um traço comum a todos eles e, conforme Victor Turner em sua pesquisa sobre os Ndembu de Zâmbia, os iniciandos são "pessoas liminares" porque se encontram em transição entre estados distintos, já não pertencem mais à classificação anterior e ainda não foram incluídos em uma nova. Eles têm uma "realidade física", mas não social, daí precisarem permanecer escondidos (1980:108).

No caso dos Mbya, essas pessoas que estão numa posição "interestrutural", como descreve Turner, recebem o nome de iñengue e ñe'enguchu, porque durante um breve lapso de tempo já não são mais kyringue ou "crianças", mas ainda não detêm o status de kuña, "mulher", e ava, "homem".

\section{A reclusão}

Quando a moça é levada até o opy, o pai constrói uma tarimba ou pequena cama estreita e curta que recebe o nome de ñiimbe, utilizando taquaras, geralmente takua pekuru (Guadua trinii). A menina deve permanecer no ñiimbe com as pernas cruzadas, tocando o chão o menos possível. A finalidade dessa tarimba é evitar que a menina seja atacada pelo yvy já, "gênio 
da terra", um dos muitos espíritos da natureza a que são vulneráveis as adolescentes na menarca.

O sacerdote Franz Müller (1989), que entrou em contato com os Mbya no Paraguai no final do século XIX, fez uma descrição do ritual de iniciação das iñengue, explicando que elas permanecem de rosto voltado para a parede em um canto escuro, num espaço isolado do restante da construção para que ninguém possa vê-las. Elas não devem se mexer e somente podem falar se lhes falarem e não podem rir.

Uma mulher de Takuapi, Yva, de aproximadamente 50 anos, lembrava-se dessa etapa da sua vida como uma dura prova. Sua irmã mais velha tinha se ocupado de "assisti-la", conforme ela expressou, enquanto esteve isolada no opy e tinha sido duríssima com ela. A mulher repetia o termo ojopy, que significa "aperta", sua irmã a "apertava", para me explicar a grande exigência à qual esteve submetida.

A respeito da duração desse isolamento, todas as pessoas entrevistadas concordaram que deve ser peteî jachy, "uma lua", ou seja, 28 dias, o tempo médio do ciclo menstrual. Mulheres entre os 40 e 50 anos de idade manifestaram que estiveram isoladas durante esse período, mas que na atualidade a reclusão seria somente de 15 dias naquelas comunidades nas quais ainda é realizado o ritual de forma completa ou até menos tempo, quando já não são acatados todos os seus aspectos e a reclusão é cumprida na própria casa. A moça deve permanecer com a cabeça coberta com uma manta ou um tecido qualquer enquanto está em reclusão e não pode olhar para as pessoas que circulam dentro do opy, deve dirigir o olhar sempre para o chão.

São aplicadas em seu rosto pinturas tradicionais ou ychy com o desenho de araku pychã, literalmente "dedos de pé do araku", que consiste nas marcas das patas dessa ave (Aramides saracura). São feitas três pequenas linhas imitando suas pegadas em cada bochecha, perto das maçãs do rosto. O araku está classificado entre as aves que pertencem a Charîa, o oponente do herói solar Kuaray na cosmologia mbya, possuindo, portanto, atributos negativos. Segundo as narrações míticas, foi criado da batida do coração de Charîa quando ele morreu carbonizado (Cebolla Badie 2000). As meninas e púberes não devem comer a carne dessa ave porque lhes ocasionaria futuros problemas na gravidez, o parto demoraria ou o bebê poderia nascer com más-formações.

A pintura destinada às iñengue é elaborada exclusivamente das ceras e do própolis da abelha nativa sem ferrão, ei ruchu (Melipona scutellaris), que também recebe o nome de kuñangue ro, "casa das mulheres", porque nos tempos primigênios elas formaram um grupo de moças em estado núbil, as quais deveriam ser entregues em matrimônio mas que não aceitaram seus 
futuros maridos, fechando-se em uma casa. Devido a esse comportamento, as divindades as transformaram nas abelhas ei ruchu que conhecemos na atualidade (Cebolla Badie 2009), existindo nesse caso um claro nexo entre as iñdngue que estão em reclusão e esta espécie, segundo este mito tão sugestivo.

Além do desenho de araku pychã, são traçadas linhas nas articulações, nos pulsos e nos joelhos para prevenir a doença que os Mbya chamam karugua e que é traduzida como reumatismo. Também são feitas linhas nas solas dos pés para protegê-los de cortes e feridas quando caminham pela floresta. Essas pinturas corporais são consideradas cuidados preventivos.

Em tempos passados evitava-se cortar o cabelo das meninas para que no momento da chegada à puberdade tivessem o comprimento suficiente para confeccionar o tetymakuaa, as trancinhas de cabelo que os adultos enrolam abaixo dos joelhos, nos antebraços e nos tornozelos. Hoje em dia já não são mais usadas, embora existam em alguns anciãos que as levam ocultas debaixo das calças. Segundo relatam os indígenas, no "tempo dos avós", as mulheres também as usavam nas panturrilhas e nos tornozelos. ${ }^{6}$ Egon Schaden (1974) registrou o uso de tetymakuaa nos três grupos guaranis que estudou ${ }^{7}$ e disse que tem uma finalidade mágica para evitar o cansaço na musculatura dos braços e das pernas, sendo indispensável nas longas caminhadas. No passado, quando ainda eram usadas as roupas tradicionais, essas cordas também serviam para sustentar o tambeao, tanga tecida com fibras vegetais.

Adolf Schuster (1929), que conviveu com um grupo Mbya no início do século XX, recebeu de presente cordões de cabelo feminino, descritos por ele como tranças de aproximadamente dois milímetros de largura e que tinham entre 30 e 60 metros de comprimento.

Fabricar essas trancinhas, sob a supervisão da avó ou de outra mulher da família era uma das tarefas a ser realizada pela iñengue enquanto estava no opy. Concluída a obra, era entregue ao líder religioso, que a distribuía entre os homens sem se importar que fossem ou não parentes da menina. Atualmente, nas poucas aldeias nas quais se continua confeccionando o tetymakuaa, ele é entregue em troca de dinheiro, porque é considerado "um trabalho", mas antes, quando não se conhecia "o dinheiro do Juruá", ${ }^{8}$ era intercambiado por bens.

Também se fazia akya, a rede de malha que já não é mais usada. Ela era confeccionada trançando-se fibras de pynõ guachu ou urtiga-brava (Urera baccifera) que previamente tinham sido tratadas. Hoje em dia à iñengue somente são ensinados a costura e o conserto de roupa.

Schaden (1974) descreve o tempo de resguardo entre os Mbya como um período de aprendizado de habilidades manuais. O ensinamento era ministrado pela avó paterna ou materna. E, além de aprenderem a trançar 
as malhas para as redes e as cordas de cabelo, lhes era ensinado como fiar e confeccionar a roupa tradicional.

Nas conversas mantidas sobre o período de reclusão foi sempre mencionado o regime ao qual são submetidas as meninas como forma de "educação": é preciso educá-las para sua vida futura como esposa e como mãe. Dessa maneira, as iñengue devem aprender a se comportar segundo o modelo de mulher na sociedade mbya, porque as mudanças não envolvem somente o corpo, mas também o status que terão a partir daí.

Viveiros de Castro, em referência aos ritos de passagem entre os Yawalapiti, explica que as transformações corporais são acompanhadas de mudanças no status social: "a natureza humana é literalmente fabricada ou configurada pela cultura. O corpo é imaginado, em todos os sentidos possíveis da palavra, pela sociedade" (2011:72).

Nessa "fabricação" são seguidos protótipos ou modelos, havendo assim certas obrigações que a menina deve cumprir enquanto está em reclusão, como permanecer calada, falar somente se falarem com ela e fazê-lo em voz baixa, fixar o olhar no chão, movimentar-se com suavidade e manter em geral uma atitude submissa. Este é o comportamento valorizado e esperado de uma mulher na sociedade mbya.

Somente naquelas que já podem ser consideradas "mais velhas", a partir dos 50 anos de idade aproximadamente, costuma ser observado um comportamento distinto: mandam nos seus familiares, falam em voz alta e participam das reuniões de caráter político na comunidade. Também ocupam um lugar de importância nas cerimônias religiosas, nas quais são denominadas kuña karai ${ }^{9}$ e estão no mesmo nível hierárquico dos homens. Essas mudanças de atitude acontecem quando as mulheres já finalizaram sua vida reprodutiva; somente a partir daí podem compartilhar os espaços de poder antes reservados exclusivamente ao sexo masculino. São essas mulheres mais velhas que vigiam as iñengue, a fim de que cumpram todos os preceitos da reclusão, entre eles receberem os alimentos adequados para o seu estado.

Diferente do que acontece na vida cotidiana, na qual não são observados horários para as comidas, exceto depois do pôr do sol quando não é recomendável ingerir alimentos, no caso da iñengue, ela somente pode comer em momentos muito bem determinados. Possivelmente, ao amanhecer, ao meio-dia e antes do anoitecer. Os alimentos prescritos para esse estado são elaborados com vegetais cultivados, em especial o milho; os entrevistados mencionaram recorrentemente os seguintes: mbaipy, ${ }^{10}$ rora $^{11}{ }^{11}$ mbojape, ${ }^{12}$ kaguyjy, $^{13}$ assim como mandio mimói, "mandioca fervida", e jety mbichi, "batata assada".

A frugalidade parece ser a regra, já que a iñengue deve comer em pequenas quantidades e não chegar a ponto de ter saciedade, regra que será 
repetida em outras situações ao longo de sua vida, por exemplo, durante a gravidez. Não deve consumir sal nem açúcar porque poderia adoecer. $\mathrm{O}$ mel está proibido porque produz hemorragias. Os méis silvestres das distintas espécies de abelhas nativas sem ferrão são mais líquidos do que o mel da abelha europeia (Apis melífera) em função do seu alto teor de água. Talvez devido a esta característica, e por analogia, evita-se seu consumo como prevenção.

As iñengue não devem consumir doces para evitar "fraqueza na conduta", como expressado pelas anciãs entrevistadas. Aparentemente, o açúcar diminuiria sua inteligência e lhes faria "andar mal da cabeça". Em síntese, comprometeria sua capacidade de discernimento, ocasionando um comportamento errado. Não obstante, nas épocas de escassez, quando não se conta com os produtos das roças, é permitido oferecer para a iñengue certas frutas silvestres, como jarakachi'a (Jaracatia spinosa), guaporoity (Plinia rivularis), guapyta ${ }^{14}$ (Arecastrum romanzoffianum), yvaporû (Pliniatrunciflora), yva viju (Eugenia pungens), aracha (Psidium sp.), ñandu apycha (Campomanesia guazumifolia), eñangapiri (Eugenia uniflora). Estas foram as espécies elencadas repetidamente pelas pessoas consultadas, principalmente as quatro primeiras, um número limitado se for levada em conta a grande quantidade de espécies de frutas que são consumidas pelos Mbya. As frutas consideradas como "dos brancos", entre elas peras e maçãs, mas notadamente as laranjas e outros cítricos, estão proibidas. Além dos vegetais cultivados, também se dá para a menina pindo ru'a, coração da palma pindo (Arecastrum romanzoffianum), cru ou fervido.

A carne está expressamente vedada durante a reclusão porque aumentaria o perigo de a iñengue ser possuída pelos espíritos de animais. Neste caso, nem sequer as fumigações realizadas com fumo de tabaco pelo líder religioso seriam suficientes para protegê-la da essência que ainda permanece na carne.

Chama a atenção que esteja proibido o consumo de kochi ou pecarí labiado (Tayassu pecari), que deve ser consumido do mesmo modo que o kaguare ou tamanduá pequeno (Tamandua tetradactyla kriegi) e o kaguare guachu ou tamanduá grande (Myrmecophaga trydactila $)^{15}$ durante a gravidez e pós-parto, quando a mulher novamente se encontra num estado em que pode ser facilmente influenciada pelas entidades da floresta. O período de reclusão das meninas constituiria assim a única época na vida dos Mbya em que é proibido comer carne, sendo uma situação muito particular, porque os ñe'ênguchu, por sua vez, podem ingerir certas partes da caça embora em pequenas porções.

Naquelas comunidades nas quais não é mais possível aceder aos recursos da floresta, a menina é alimentada com comidas preparadas à base de farinha de milho, leite, mandioca, batata e as frutas silvestres que se 
consiga obter. Quando a moça recebe os alimentos, não deve olhar de frente a mulher que os entrega, nem pode falar com ela.

Enquanto permanecer no opy, uma das suas avós ou uma anciã de seu próprio grupo de parentes aconselha-a a respeito do que se espera dela no futuro como mulher e como mãe. Nesses discursos lhe é constantemente lembrado que foi isolada para seu próprio benefício, para que saiba cuidar de sua saúde e para que não seja uma pessoa "mal-educada", no sentido de ser desobediente, desrespeitosa, desatenta ou preguiçosa - condutas desaprovadas entre os Mbya.

A referência à maternidade era uma constante quando os indígenas explicavam a finalidade dos conselhos que recebe a iñengue das anciãs, devendo aprender todos os cuidados para levar a bom termo uma gravidez, ter um parto rápido e dar à luz uma criança sadia. Desse modo, durante o isolamento, seriam enfatizados a conduta e os valores que deve observar a moça ao longo da sua vida, especialmente no novo papel de mãe que em breve terá de assumir. Entre os Mbya, o ritual parece marcar a mudança para a possibilidade da maternidade mais do que o começo da vida sexual.

As iñengue não necessariamente são virgens, segundo os relatos coletados, pois as moças costumam estar "acompanhadas", isto é, morando com um parceiro ainda antes da menarca.

Os Mbya continuam praticando a poligamia em certos casos, mas de maneira discreta e camuflada para evitar as reações negativas dos distintos agentes brancos que intervêm nas comunidades. Existe entre eles um tipo de arranjo matrimonial precoce, no qual é pedido aos pais de uma menina de 7 ou 8 anos de idade que ela seja entregue ao homem que será seu futuro marido ou para a família deste para a sua manutenção.

Aparentemente, em alguns casos, o convívio começa de maneira imediata, o que foi observado pelo naturalista Ambrosetti (1898) em uma de suas estadias com os Mbya, tecendo comentários espantados sobre esse costume, também registrado por Viveiros de Castro (1992) para os Araweté, que consideram que as meninas devem ser iniciadas sexualmente para depois poderem ter menstruações com normalidade.

\section{Vulnerabilidade perante os espíritos}

Enquanto permanece na casa de cerimônias, a menina somente pode sair para o exterior para fazer suas necessidades fisiológicas ${ }_{1}{ }^{16}$ o que deve realizar com prontidão. É coberta então a cabeça e ela caminha olhando fixamente para o chão, acompanhada pela mulher que cuida dela. 
Os Mbya explicam a reclusão à qual é submetida a iñengue como forma de proteção, já que esse período da vida de uma mulher seria de máxima sensibilidade perante os espíritos da natureza.

Schaden (1974) afirma que nos três grupos Guaranis que estudou, o que denomina de "eclosão pubertária" é a manifestação da crise mais delicada na vida da mulher. Chama esse estado de ojeko aku, palavras que significam literalmente "estar em estado quente", no sentido talvez de fragilidade diante dos perigos. León Cadogan (1992b) o traduz como "aquele que está submetido a regime alimentício ou a tratamento", porque estas são as precauções que deve ter quem se encontra em tal circunstância.

A iñengue que não recebe os cuidados necessários e perambula pela floresta ou pelas roças pode ser uma presa para distintas entidades. Esses entes invisíveis têm a faculdade de enganar as moças púberes aparecendo perante seus olhos com forma humana. Aparentemente, nas diferentes etnias Guaranis da região, essas entidades estão conformadas principalmente pelos espíritos de animais (Schaden 1974; Chase Sardi 1992; Mayntzhusen 2009) que tomam posse da alma da moça.

Os Mbya também se referem a esse tipo de possessão, mas quando falam dos perigos que corre a iñengue, falam indefectivelmente de yvyra ñe'ê ou "a alma da árvore", de ka'aguy rovapy ja, que poderia ser traduzido como "o dono de tudo o que existe na floresta", e de mbai'i, um duende malévolo que aparece diante das moças com aspecto de um homem de baixa estatura. Os indígenas descrevem a possessão da alma da iñengue por essas entidades utilizando o termo ojepota, que é traduzido como "se apaixonar se juntar sexualmente com um animal mítico ou espírito" (Cadogan 1992b). Esses espíritos enganam as moças apresentando-se com falsas aparências, por isso deve-se evitar o contato visual com essas entidades, que somente podem ver aqueles que estejam em alguma etapa especial da vida, como as iñengue e os ñe'ênguchu, porque através do olhar produzir-se-ia o "encantamento" desses entes.

Enquanto as meninas estão em isolamento, costuma-se banhá-las com uma preparação feita pelas mulheres, deixando macerar o ta'y re ou larvas da abelha eira pu'a (Trigona spinipes), conhecida pelas suas propriedades para o tratamento de doenças associadas à perda de sensatez provocada pelos $m b a^{\prime} e$ vai, entes malignos da floresta (Cebolla Badie 2009). Neste caso, considera-se muito eficaz esse remédio para evitar que elas sejam atraídas por eles.

O duende chamado mbai'i parece ser um dos principais perigos para as moças, porque não somente se apropriaria de sua alma, ${ }_{1}^{17}$ mas também poderia engravidá-las, já que é possível ter essas entidades como parceiros sexuais. 
Quando os Mbya falam em "tirar a consciência" ou "perder o entendimento", referem-se à perda da alma, que pode ser temporária, mas se a situação se prolongar, sobreviria a morte da pessoa afetada. Se uma adolescente apresenta sintomas correspondentes aos de um encantamento, as pessoas se reúnem no opy e o líder religioso pede às divindades, por meio de orações e farta fumaça de tabaco, que a entidade que se apropriou da moça a liberte para que sua alma retorne.

Verã Mirî, cacique da comunidade de Takuapi, relatou-me a experiência vivida na aldeia próxima de Marangatu pouco tempo antes, onde precisaram reunir os três opygua, ou líderes religiosos, para que juntassem suas forças numa cerimônia conjunta celebrada para libertar uma iñengue do espírito que a tinha possuído. Era um caso grave; a moça padecia de um forte desequilíbrio mental que tinha começado repentinamente durante sua primeira menstruação. Considerava-se que o ñe'ê ou "palavra-alma" a havia abandonado pela ação de algum espírito da floresta. Foram feitas orações e danças, das quais participaram os membros da comunidade e também outras pessoas que tinham acudido acompanhando os xamãs.

Segundo seu relato, fizeram dançar a moça dentro do opy enquanto cantavam para NandeRu Ete. ${ }^{18}$ Então começou a fazer calor, tanto que os assistentes passaram a se sentir sufocados. Era a moça que expelia o calor pelo efeito do espírito que a possuía. As orações e as fumigações com as fumaças dos cachimbos dos líderes religiosos continuaram até que a iñengue caiu no chão e do seu corpo emergiu um enorme sapo que tinha usurpado sua alma.

A menção ao calor que saía do corpo da adolescente e que teria afugentado sua alma quando o espírito do animal se apoderou dela remete imediatamente ao conceito de ojeko aku, ou "estado quente", no qual se encontram as pessoas que estão passando por algum período de crise em sua vida.

Aparecida Vilaça expressa a respeito da concepção da instabilidade da alma e sua possível substituição por outras entidades, presente em diversas culturas amazônicas, que "essa ambivalência na identidade, apesar de estar fortemente marcada durante o período pós-parto, acontece em distintos momentos da vida, entre eles na iniciação, e muito frequentemente implica a possível perda da identidade humana propriamente dita" (2002:349).

Entre os Mbya, os momentos mais críticos e perigosos do ciclo vital parecem ser o nascimento, a puberdade e as situações de doença. Em todos esses casos, a alma da pessoa encontra-se em um estado de grande sensibilidade e pode ausentar-se do corpo ou ser capturada por essas outras almas não humanas que ocupariam seu lugar.

Conforme explica Silvia Citro em seus trabalhos com os Tobas, "a concepção da pessoa e sua corporalidade são definidas a partir de uma série 
de múltiplas e intensas relações com o mundo natural, a corporalidade estando aberta para ser influenciada e para influenciar nesses âmbitos" (2008:44). Esta seria também uma interpretação válida para os Mbya, em que a constante interação com as entidades da natureza, apesar dos perigos que implica, marcaria a identidade como ser humano e também seria parte da definição de pessoa segundo os cânones da cultura.

Enquanto dura a reclusão da menina, ela é banhada com água de cinzas ou tañimbury porque, segundo explicaram os indígenas, assim como é preciso evitar os cursos de água, também não se pode tomar banho com "água viva". Desse modo, este tipo de lixívia que é preparada com as cinzas retiraria da água qualquer essência que pudesse causar dano à menina, tornando-a inofensiva. Finalmente, ela é molhada com a decocção das folhas e a casca do ygary (Cedrela fissilis), árvore de grande significado na cultura mbya; é um dos yvyra ñe'êry, "árvores da palavra-alma". Passam por seu corpo as folhas do yvaro (Prunus sp.), cujo nome significa "fruta amarga" e são tóxicas quando ingeridas. O yvaro é renomado na farmacopeia mbya, sendo utilizado nos casos de feitiçaria e maldições. Trata-se o enfermo lavando-o com a água das folhas maceradas, ao mesmo tempo em que o opygua faz orações. Essas espécies de árvores são consideradas como Poá, ou "remédio", para as iñengue, e os indígenas as comparam com o ychy, a pintura que é aplicada na moça para protegê-la de doenças. O yvaro é reconhecido como o melhor "remédio" pelo seu forte cheiro, embora o ygary ou cedro também tenha um cheiro "horrível", segundo os Mbya. Essas espécies afugentariam assim os espíritos que rondam a menina, aparentemente atraídos por um aroma especial que possuem os iniciandos nessa fase.

Os meninos e as meninas expelem um cheiro, hêãkua, dizemos, que atrai as almas da floresta. Eles têm um cheiro forte que o vento leva e também a correnteza na água, vai muito longe, por isso atrai as almas que estão longe. Nós, os humanos, não os percebemos, somente os espíritos (Verã Guyra de Jejy).

A palavra hêãkua remete aos aromas agradáveis na língua mbya, por exemplo, ao perfume das flores. Esse cheiro é atrativo para os espíritos, portanto, é preciso cuidar das moças e dos moços no período de iniciação de distintas maneiras, uma delas é por meio dos banhos medicinais com as espécies de árvores que expelem cheiros fortes, que diminuiriam o "aroma" dos adolescentes e afugentariam os maus espíritos.

Eduardo Viveiros de Castro (2011) conta sobre os Yawalapiti que para eles os espíritos possuem um olfato hipersensível e odeiam o cheiro das pessoas, especialmente daquelas pessoas que se encontram em estado 
transicional, como jovens em reclusão púbere, aprendizes de xamãs e pais em isolamento. Todas elas são pessoas com restrições alimentares e em abstinência sexual que expeliriam um cheiro especial. A explicação do confinamento como uma forma de proteger a iñengue contra as entidades malignas foi uma constante no discurso dos indígenas.

Lévi-Strauss, referindo-se aos Tikuna, afirma a respeito da cerimônia de iniciação das moças que ela "simboliza um combate travado pelos humanos para proteger a moça púbere dos espíritos que a ameaçam durante esse período crítico de sua vida" (2005:308). A ameaça que significa o assédio dos espíritos da floresta e o temor que inspira a possibilidade de interagir com eles exerceriam um poderoso controle para que as púberes não se desviem do que estabelecem as normas e aceitem os preceitos de seu futuro comportamento.

Victor Turner (1980:122) recomenda para os estudos sobre ritos de passagem focar a atenção nos fenômenos e nos processos relacionados aos períodos de transição, que são os que de maneira paradoxal expõem os fundamentos da cultura. Na iniciação das meninas mbya esse período corresponderia ao tempo no qual permanecem em isolamento e no qual lhes é exigida uma atitude totalmente submissa, para permitir que lhes sejam inculcados os valores e os comportamentos que delas se esperam na vida adulta que estão prestes a começar.

Peter Gow (2001), na sua etnografia sobre os Piro, compara a condição da moça reclusa durante a iniciação com um feto no ventre materno, já que compartilham as características de estarem crescendo na escuridão e adquirindo um "corpo".

Ainda conforme Turner (1980), no que ele chama de as três fases distintivas dos ritos de passagem - separação, liminaridade e incorporação - a primeira fase, a de separação, supõe uma conduta simbólica que marca o afastamento do grupo, no caso dos $M b y a$, isso seria marcado com o corte dos cabelos da menina e sua reclusão.

$\mathrm{Na}$ fase seguinte, liminaridade, o sujeito encontra-se em um estado ambíguo devido ao fato de que já não tem mais os atributos do passado, como criança, e também não possui ainda os atributos do futuro, como jovem mulher. Nessa ambiguidade, em que a situação da iñengue se assemelha a de um feto, ela está na penumbra, deve se manter silenciosa, seus movimentos são limitados. A não ser pelas rápidas saídas para o exterior com a cabeça coberta, permanece o tempo todo na pequena tarimba ou ñimbe que, conforme alguns informantes, por suas dimensões, não permite que se estique, o que a obriga a dormir encolhida. Somente pode comer o que lhe é oferecido e não pode tomar banho sozinha, deve deixar que outra mulher 
o faça por ela. Sua vontade parece ter sido anulada e lhe é exigido um autocontrole que será uma constante na sua vida como adulta.

$\mathrm{Na}$ terceira fase, de incorporação, o ritual consumou-se e a pessoa reintegra-se à sociedade.

\section{Retorno à sociedade}

Entre os Mbya, ao contrário do que acontece com outros povos indígenas (Citro 2008; Gow 2001; Mendes dos Santos 2006), o final do período de reclusão não é marcado por uma festa ritual. Ainda que todas as pessoas consultadas concordassem que o tempo de resguardo dura aproximadamente 28 dias, peteî jachy, "uma lua", houve algumas variações a respeito de uma segunda etapa de isolamento, durante o ciclo menstrual seguinte, no qual a reclusão seria menor. Aparentemente, na atualidade, o ritual de iniciação parece ter sido reduzido a uma única reclusão que, segundo distintas versões, duraria entre cinco e 20 dias.

De qualquer maneira, a "educação" continua mesmo depois da iñengue retornar à vida familiar. Não pode permanecer ociosa e lhe são atribuídas diversas tarefas que deve cumprir de forma rápida e esforçada, sempre sob a vigilância da mulher que dela cuidava enquanto estava no opy. Essas tarefas, que na divisão sexual do trabalho na sociedade mbya pertencem ao universo feminino, já são realizadas pelas meninas antes da menarca. Assim, não há um aprendizado dessas atividades, a mudança consiste na atitude que devem manter quando as realizam e na responsabilidade que elas implicam. Enquanto são meninas, muitas dessas tarefas são feitas como parte das brincadeiras, imitando suas mães e irmãs mais velhas, depois será uma exigência da família, mas nunca com o rigor que adquire no período entre duas reclusões ou nos meses posteriores à finalização do isolamento. Algumas vezes estão presentes duas ou mais moças nos rituais de passagem, então elas realizam conjuntamente as tarefas e são vigiadas somente por uma pessoa.

A iñengue continua numa situação de vulnerabilidade ante os "entes invisíveis", como os Mbya costumam chamá-los, inclusive depois de finalizada a reclusão, embora com menor intensidade. Seu corpo ainda exala o "aroma" que os atrai e por conta disso deve tomar especial cuidado com os rios e os córregos, não pode mergulhar neles com fins higiênicos nem de lazer. Quando for procurar água para transportá-la até a casa ou lavar as roupas, deve cumprir tais tarefas com prontidão, sem olhar ao redor, porque os perigos ainda a rondam. Precisa ter especial cuidado quando se dirige à 
floresta ou aos hortos para fazer suas necessidades fisiológicas, porque esse é um momento de grande risco; tem que agir com rapidez e sempre deve estar acompanhada por outra menina.

Por vários meses depois do seu retorno à vida familiar não pode lavar a roupa diretamente na água do córrego, precisa retirar água num recipiente e nele lavá-la, já que a água corrente transporta seu cheiro e atrai os espíritos. Lévi-Strauss oferece-nos a seguinte explicação sobre essas precauções: “à diferença da água estancada, que é uma água neutralizada, a água corrente constitui, pois, o término marcado. É mais poderosa e mais eficaz, mas também mais perigosa: habitada pelos espíritos, ou em direita relação com eles" (2005:157).

Ao anoitecer, a moça já pode compartilhar das reuniões familiares junto ao fogão, mas deve manter uma atitude tranquila e falar somente o indispensável, como uma forma de se proteger contra os espíritos que vagam na noite.

Depois dessa espécie de jejum a que é submetida a iñengue enquanto está no opy, uma vez que está no exterior, amplia-se a variedade de alimentos que pode ingerir, mas não a sua quantidade. Tem que continuar comendo pouco, como uma maneira, segundo explicam os indígenas, de aprender a ser solidária, a compartilhar a comida e a nunca ser mesquinha. Os Mbya apontam essa atitude como própria da sua cultura, e ela é altamente valorizada porque faz parte do mborayu, "amor pelos outros", que permite manter boas relações com as divindades.

Nos primeiros dias, a dieta não é diferente daquela que tinha seguido enquanto estava na casa de cerimônias, a alimentação baseando-se principalmente em pratos preparados com milho, mandioca e batata. A moça deve reprimir seu desejo de comer. Quando é trazida uma peça de caça à aldeia e as mulheres a preparam publicamente, a iñengue não pode permanecer no lugar e lhe é atribuído algum tipo de tarefa a fim de que ela se afaste e se concentre somente naquilo que está fazendo.

Uns dias depois de sair para o exterior, mesmo que as restrições das carnes vermelhas continuem, já poderá comer peixe e certas aves. As carnes que a moça vai ingerir são fumegadas com fumo de tabaco dos cachimbos petŷngua para diminuir as qualidades do animal a que pertencem.

Somente depois do período de uma lua é que lhe será permitido ingerir coisas doces, especialmente os diversos méis silvestres. O sal continuará a ser um elemento proibido ainda durante muito tempo porque poderá ocasionar doenças, atingindo especialmente o estômago e produzindo fortes dores. As larvas de insetos das quais os Mbya tanto gostam também podem ser consumidas com moderação nessa etapa, mas somente a denominada ycho pytã ou "larva vermelha" de um coleóptero. Transcorridos alguns dias lhe 
será permitido comer carne de pecari labiado, naquelas aldeias onde ainda pode ser caçado. No passado, quando a fauna abundava, também podia comer tamanduá. Essas carnes são classificadas como cho'o porã, "carne boa" no sentido de pureza.

Precisam se passar mboapy meme jachy, "seis luas", para que a moça possa consumir carnes vermelhas com certa liberdade. Mas, mesmo assim, não deve comer quati nem as diferentes espécies de cervos, porque essas carnes são denominadas aja, que é traduzido como "impura" ou "contaminada". A carne de quati produz parasitos, e a espécie de cervo chamada guachu pytã (Mazama americana) é especialmente proibida para as adolescentes, porque é te'o'ã já, cuja tradução é "dono dos ataques e tonturas", uma vez que sua carne, quando consumida em determinados momentos do ciclo biológico, produz esses sintomas. A moça sofre desmaios e ataques que os indígenas comparam com a epilepsia. Depois que volta a si, seu entendimento fica afetado, "não fica bem da cabeça", explicam os Mbya. Essa doença, chamada te'o' $o^{\prime}$, descrita como similar à epilepsia, se referiria em verdade ao abandono temporário da alma.

Tenho encontrado algumas divergências a respeito da finalização da condição de iñengue e sua mudança para kuña tai, "mulher", ou seja, sobre a conclusão do ritual de passagem para a vida adulta.

Diz-se iñengue páma quando terminam os cuidados específicos e a moça se reintegra por inteiro à sociedade, podendo então começar ou reiniciar sua vida sexual. Alguns dos informantes afirmaram que isso acontece quando a menstruação chega pela terceira vez, então a moça já é uma kuña tai, mas deve continuar observando as restrições alimentares e de movimentos. Uma das anciãs disse que na sua juventude as moças somente estavam em condições de formar um casal e de cogitar uma gravidez quando seu cabelo tivesse crescido até a metade do braço.

Deste modo, se passava mais de um ano desde o começo da reclusão e o momento em que se considerava que o processo havia finalizado totalmente, prolongando-se assim a idade para a procriação.

\section{Ñe'ênguchu}

À diferença do ritual de passagem das meninas, no qual elas devem permanecer reclusas, a iniciação dos varões é externa e sempre coletiva. Costuma-se distinguir os ñe'ênguchu nas aldeias como turminhas de rapazes de idades entre os 12 e os 15 anos que são lideradas por um adolescente um pouco mais velho, o cabo'i, em referência aos graus militares impostos na época 
colonial aos grupos guaranis e que os Mbya continuam a utilizar na sua organização política.

Em geral, os iniciandos são chamados de chondaro'i, "soldado". Nas tarefas de vigilância ou salvaguarda da ordem que devem realizar nas escolas ou nas festas que são organizadas nas aldeias, eles estão sob as ordens de um cabo'i de aproximadamente 18 ou 19 anos, facilmente reconhecível pelo porrete de madeira que leva preso à cintura.

Dependem do sargento primeiro da comunidade, que costuma se localizar no segundo ou terceiro nível hierárquico depois do cacique e é geralmente um yvyra'ija, "dono da vara", como são denominados os homens adultos que desempenham um papel importante nos festejos religiosos. É esse sargento primeiro quem fala com eles durante as noites antes que a turma de chondaro'i se organize para a vigilância noturna da aldeia, missão que cumprem sob a supervisão do sargento, usualmente até meia-noite.

Se abandonarmos as denominações militares que utilizam os Mbya para explicar a hierarquia de poder no seu sistema político e nos remetermos à organização tradicional, os ñe'ênguchi cumprem tarefas coletivas sob a supervisão direta de outro adolescente, que já é considerado um homem desabrochando, porque teria terminado sua etapa de ñe'ênguchu. Todos eles são responsabilidade de um yvyra'ija encarregado de aconselhá-los a respeito de seu comportamento e do que se espera deles na sua vida adulta.

Os rapazes no período de iniciação cumprem uma espécie de serviço à comunidade e devem aceitar as ordens de qualquer pessoa mais velha da aldeia e executá-las com rapidez. Seu trabalho se torna público e é exigido continuamente, tal como explica Verã Guyra da aldeia de Jejy:

Ne'ênguchu tem que levantar quando amanhece, trazer lenha, procurar água, não deve falar muito com os companheiros, não pode brincar, não pode ficar sentado, tem que fazer os trabalhos. É levado para o mato e é ensinado a caçar, a fazer as armadilhas. Antes lhe eram ensinadas todas as coisas que eram feitas, tem que aprender $100 \%$.

Karai Tataendy, um ancião de aproximadamente 70 anos de Takuapi, lembrava sua época de ñe'ênguchu como uma etapa de grande rigor, em que foi testada sua vontade e seu autocontrole, porque não podia se recusar a fazer o que lhe ordenavam.

Tinha que machadar ${ }_{1}^{19}$ mandavam machadar em qualquer lugar. Você tinha que trabalhar... na roça de qualquer um, você tinha que trabalhar. De manhã não davam comida, tinha que trabalhar só, não podia comer, a não ser em kuaray 
mbyte (o meio-dia). Por isso até hoje eu estou acostumado assim, a não comer, a aguentar sem comer.

Essas atividades a que são obrigados os adolescentes, e para as quais são necessários muito controle de si e destrezas físicas, lembram os treinamentos que costumam acompanhar em outras culturas os rituais de passagem na preparação dos jovens para seu futuro status de guerreiro (Lévi-Strauss 2005) e que, com certeza, também existiram entre os Mbya. Talvez as atuais tarefas de vigilância noturna, o trabalho extenuante e os jejuns constituam remanescentes de outros tempos.

Os rapazes devem aprender a construir uma casa de estilo tradicional, conhecer as espécies de árvores que são utilizadas na construção, saber machadar apropriadamente as árvores e cortar as canas que utilizarão, além de preparar as cordas para amarrar as distintas partes. A cordoaria mbya é uma das artes que também estão se extinguindo, substituídas por arames e cabos que são comprados nos povoados. As resistentes cordas trançadas fabricadas com guembepi, as raízes aéreas do guembe (Philodendrum bipinnatifidum) descritas com admiração por Ambrosetti (1898) e Schuster (1929), tinham múltiplos usos, eram fundamentais na construção das moradias e das casas de cerimônia, na elaboração das armadilhas e na fabricação de arcos. Mas também eram utilizadas nos recipientes de cabaça ou y'akua, naqueles em que eram transportados água e mel, ou onde eram armazenados grãos no passado, e igualmente na fabricação de cestos e peneiras. A cestaria é uma tarefa que não só as mulheres, mas também os homens realizam e o seu aprendizado é outra das exigências que devem cumprir os ñe'ênguchu.

Quando os indígenas me relatavam as tarefas que deviam cumprir os adolescentes nesse período, enfatizavam o serviço aos mais velhos como um modo de se preparar para serem bem recebidos na família da sua futura esposa. Esse treinamento para desempenhar o papel de genro é de grande importância devido às características do sistema de matrimônio no qual os varões, passado um tempo após a iniciação, abandonam a aldeia e visitam outros assentamentos, seguindo os nexos de parentesco com o intuito de "arrumar namorada". Quando a moça é eleita, eles devem agradar os pais levando-lhes lenha, provendo-lhes água e caçando para eles. Segundo a norma, a mulher não tem poder de escolha, são seus progenitores que decidem. No momento em que sogros e genro chegam a um acordo e o novo casal começa o convívio na casa familiar, o rapaz deve continuar trabalhando para eles.

Entre os Mbya, o padrão de residência mais frequente é a uxorilocalidade, pelo menos durante os primeiros anos ou até o nascimento do segundo filho. Depois, costumam construir sua própria moradia, mas continuam 
a conformar a família extensa à qual pertence a moça e da qual o jovem passa a ser um aliado. Essa situação pode se manter durante a vida toda ou somente por alguns anos, quando o novo casal resolve morar na aldeia de origem do rapaz e este volta a se unir ao seu grupo patrilinear, embora continue demonstrando lealdade ao sogro.

Nessa breve descrição podemos observar que a relação genro-sogro é fundamental e, com certeza, era mais ainda em tempos passados quando os tekoa ${ }^{20}$ constituíam fortes unidades políticas, unidas entre si por redes de parentesco e afinidade.

Parte desse treinamento e aprendizado da etiqueta social é a sobriedade no consumo de alimentos e sua constante distribuição. O caçador precisa distribuir a peça obtida entre os membros de sua família extensa e, se for de grande tamanho, com a aldeia toda. Na cultura mbya a glutonaria é considerada uma falta grave que deve ser punida, os ñe'ênguchu somente podem comer quando lhes é permitido e fazê-lo em quantidades racionadas, têm que aguentar os jejuns a que são submetidos sem demonstrar ansiedade ou desconforto. A variedade de alimentos que podem consumir é mais ampla do que para as iñengue; além dos produtos vegetais, a eles são permitidos o sal, os doces e algumas carnes também. A ênfase está colocada na quantidade, como uma maneira de educar o futuro caçador, que precisará alimentar sua família e dar prioridade a essa obrigação.

As carnes que vão ser consumidas pelos ñe'ênguchu também têm de ser previamente fumegadas com a fumaça do tabaco. Embora durante o período de iniciação os rapazes possam consumir carnes vermelhas, eles não devem comer aquelas consideradas aja ou "poluídas" e que são as mesmas que estão vedadas às meninas quando, meses depois de sua reclusão, é incluída a carne na sua dieta. Porém, no caso dos varões, existe outra peça classificada como aja, o tapi'i ou anta (Tapirus terrestres), que os indígenas chamam de cho'o guachu, "carne grande", em função do tamanho do animal; é considerada como a mais perigosa das carnes proibidas. Os indígenas entrevistados expressaram que, mal tenham completado o período de iniciação e os rapazes adquirido o tom de voz definitivo, podem se alimentar com a carne de qualquer animal.

O tempo de iniciação dos varões prolonga-se por vários meses, nos quais recebem constantes conselhos e recomendações dos avós da comunidade, homens e mulheres, especialmente nas noites em que os ñe'ênguchu tornam-se altamente vulneráveis ao ataque dos espíritos. Caso não tenham de cumprir as rondas noturnas de vigilância, que sempre são realizadas em grupo, os rapazes permanecem sentados em silêncio junto ao fogão, escutando as palavras dos mais velhos, recebendo "educação", como dizem os Mbya. 


\section{O assédio das entidades não humanas}

Quando anoitece, os ñe'ênguchu, como as iñengue, já não podem mais ingerir alimentos porque a comida produz um cheiro corporal característico que atrai os mbogua - a segunda alma dos mortos - que vagueiam pelas noites e que podem atacar as pessoas que se encontram em situação de vulnerabilidade, como aquelas que estão transitando por algum dos períodos de ojeko aku ou "estado quente", experimentado pelos adolescentes na etapa de iniciação.

Durante as noites, os rapazes não devem adentrar a floresta sob quaisquer circunstâncias. Quando acompanharem seus pais nas incursões de caça em horários diurnos, eles precisam caminhar rápido, não se afastar dos outros e não dar atenção aos barulhos estranhos que possam escutar, porque esta é uma das armadilhas que colocam os espíritos para os atraírem, principalmente o temível mbai'i, que também possui os rapazes apresentando-se na sua versão feminina. Eles o enxergam como uma jovem mulher que os chama, então a seguem pela floresta até desaparecerem sem deixar rastros.

Os ñe'ênguchu também devem ser cuidadosos na sua passagem por locais onde há remansos ou cascatas, eles têm que cruzá-los rapidamente e se afastar como prevenção contra os ija ou "donos" que habitam esses locais e poderiam se apropriar da sua alma. Como acontece com as meninas nessa etapa, os rapazes têm hêãkua, ou "aroma" característico que atrai os espíritos, por isso não podem tomar banho nos rios e nos córregos, devendo evitar principalmente as águas turbulentas.

Nos cursos d'água ronda também outro perigo, a piragui, um espírito feminino que atrai especialmente os ñe'ênguchu, que habita em cavernas nas profundezas e é a "dona dos peixes". Segundo explicam os indígenas, a piragui segue o cheiro que exalam os rapazes e vai procurá-los, levando-os para sua casa debaixo d'água, de onde já não retornam mais. É então quando se diz: ojepota piraguíre, o rapaz foi possuído por esse espírito que se apaixonou por ele.

Os ñe'ênguchu devem apurar desta maneira os cuidados, sendo-lhes recomendado, inclusive, urinar numa árvore, escondendo-se para que nenhum dos espíritos que rondam por ali possa enxergar seu sexo; caso contrário, aumentaria o perigo de se apaixonarem por ele, e o atrairiam até levá-lo embora. Existe uma forte conotação sexual nas explicações que me foram dadas pelos indígenas sobre a relação com esses entes da natureza que se apresentam com forma humana para atrair os adolescentes até fazê-los perderem a razão ou desaparecer. As pinturas ou ichy seriam usadas como remédios preventivos, já que teriam o poder de repeli-los. Assim como os ojegua, ou "enfeites", como os Mbya chamam as pinturas faciais 
destinadas à iñengue, elaborados exclusivamente com a cera da abelha ei ruchu, que na mitologia foi uma mulher nos tempos primigênios, também para os rapazes são utilizados produtos da abelha jate'i (Tetragonisca angustula), que pertenceu ao sexo masculino antes de ser convertida pelos deuses nessa melífera.

Quando perguntava sobre as pinturas faciais nos homens, as pessoas entrevistadas faziam um verdadeiro exercício de memória e, quando sentados em grupo, isso provocava uma série de comentários e debates em que cada um tentava contar o que lembrava. Aparentemente, os homens pararam de usar os ojegua porque tinham que realizar trabalhos agrícolas e de limpeza do mato para os brancos e utilizar as pinturas significava se expor à zombaria e aos comentários discriminatórios.

Até algumas décadas atrás, os rapazes usavam um desenho chamado kerendy gua, que consistia no traçado de uma linha sobre o lábio, como se fosse um bigode fino. Também desenhavam cruzes, kuruchu, em ambos os lados do rosto e uma linha na testa. Na cultura mbya, as cruzes significam os quatro pontos cardeais ou os quatro ventos da abóbada celeste. Na atualidade, algumas comunidades continuam a usar as linhas nos pulsos, nos joelhos e nas plantas dos pés, bem mais discretas e que servem para prevenir na velhice a doença chamada karugua ou reumatismo.

\section{Tembeta}

No passado, o ritual de iniciação para a maturidade sexual incluía a perfuração do lábio inferior e a introdução de um pedacinho de cana ou outro material chamado de tembeta, símbolo da masculinidade entre os Mbya (Cadogan 1992b) e que era distintivo desta etnia até poucas décadas atrás. ${ }^{21}$

Em outros grupos guaranis o ato de pôr o tembeta apontava o fim do ritual de iniciação dos varões e era feito em meio a uma cerimônia dirigida pelo xamã, proibida para as mulheres (Schaden 1974; Fausto 2005), mas para os Mbya não parece ter sido tão importante.

Os indígenas disseram que o tembe kuaa, "orifício do lábio", era feito quando os rapazes começavam a "ficar ñe'ênguchu", ou seja, no início do processo de mudança de voz, e esse ato não era realizado no opy e nem era acompanhado de qualquer celebração especial. A perfuração era feita pelo pai do rapaz ou por qualquer outro homem adulto com o estípite de uma folha da palmeira pindo, chamado de pindo roykã, que eles queimam até ficar duro. Após uns dias era retirado, e no seu lugar era colocado um pedacinho da cana takuarembo (Chusquearamosissima). 
Quando conversávamos sobre este tema, os indígenas raramente utilizavam a palavra tembeta, que Müller (1989) traduz como "pedra do lábio". Acredito que seja mais adequado o termo tembe takua mencionado por Cadogan (1992b), já que seu significado é "cana do lábio". A maioria das pessoas entrevistadas referiu-se ao uso de espécies de bambu, especialmente o takuarembo, que já mencionei, e também a pequenos ossos de aves, como o inambu (Rhynchotus rufescens). Quase ninguém se lembrava do uso de palitos de resina ou de âmbar, conforme descritos por Müller (1989), Schaden (1974) e Ambrosetti (1898). Este último autor explica que observou entre os Mbya esses enfeites labiais sendo fabricados em resina, entre 10 e 20 centímetros de comprimento, e que, para não quebrá-los ao andarem pela floresta, os indígenas os substituíram por palitos da cana takuarembo (1898:65).

Os Mbya sempre se referiram ao ato de colocar o tembeta no ñe'ênguchu com a finalidade de se tornarem homens calados e sérios, que não são "charlatães", como explicam em espanhol, e que sempre utilizariam a palavra justa. Na cosmologia mbya o uso do enfeite labial é atribuído ao deus Tupã que possui um tembeta de âmbar e, quando anda pelos céus, sentado no seu apyka, pequeno banco zoomorfo, o brilho do tembeta ocasiona os relâmpagos que podem às vezes ser vistos nas lonjuras sem que as trovoadas sejam ouvidas (Cadogan 1992a).

No passado, o tembeta era um signo de pertencimento à etnia; um homem não podia ser considerado mbya se não tivesse o tembe kuaa ou "orifício labial". Schaden (1974) explica que, para poder se casar, ele era necessário e que aquele que não o tivesse não poderia participar dos cânticos religiosos nem das danças na cerimônia do ñemongarai, ou seja, não poderia ser considerado um mbya de pleno direito.

O ancião Verã, respeitado líder religioso de Takuapi, já falecido, que ainda tinha a marca do tembe kuaa debaixo de seu lábio, explicou-me há vários anos, numa breve conversa sobre o tembeta, que em sua juventude este era um "documento". Lembro que ele enfatizou a pronúncia desta palavra em espanhol, comparando o tembeta com o documento nacional de identidade obrigatório nos atuais estados em que foram divididos os territórios tradicionais mbya e sem o qual uma pessoa é considerada praticamente inexistente.

Segundo os relatos dos anciãos, naqueles tempos, quando os indígenas em seus deslocamentos pela floresta encontravam-se de repente com outras pessoas, a primeira coisa que eles faziam era observar se elas tinham tembeta com o intuito de evitar confrontos com grupos inimigos.

Tal como aconteceu com as pinturas faciais, alguns homens velhos me disseram que seus pais optaram por não lhes perfurar os lábios para que, ao "saírem" para trabalhar para os brancos, não fossem alvo de zombarias. 


\section{Considerações finais}

Os rituais de passagem para a maturidade sexual entre os Mbya reforçariam as características do que é concebido como os universos feminino e masculino nesta cultura. Durante o período em que os adolescentes se convertem em "seres transicionais" (Turner 1980), já que estariam "entre e no meio de" status diferentes na sua sociedade, são submetidos a um rigoroso treinamento em que são reafirmados os conhecimentos que deve ter um mbya nessa idade a respeito das atividades que, em outros tempos, permitiam a sobrevivência, mas também a vida em comunidade.

Moças e rapazes não apenas recebiam ensinamentos sobre como fiar, tecer no tear, costurar, fazer as cordas de cabelo feminino, fabricar cestos, montar armadilhas, usar o arco e a flecha e construir casas, entre outras habilidades, ${ }^{22}$ como também deviam "escutar" dos avós os preceitos destinados a convertê-los no que se considera que deve ser um homem e uma mulher na cultura mbya.

Sobre o caráter coletivo da cerimônia dos rapazes e o tratamento individualizado, em confinamento, das moças, os indígenas entrevistados sempre frisaram que assim era seu "sistema" em referência aos papéis feminino e masculino: "As mulheres têm que ficar quietas, imóveis, e os homens têm que se mexer, trabalhar, caminhar rápido. Eles são os que depois deverão sair" (Verã Mirî de Takuapi).

O que esse homem quis dizer com "sair" é que os jovens devem abandonar a aldeia onde moram seus pais ou sua família de origem para procurar sua futura esposa em outras comunidades. A mulher, por sua vez, permanece junto com seus familiares pelo menos durante mais tempo do que o varão e, enquanto é jovem, espera-se dela uma atitude reservada e tranquila e, acima de tudo, que obedeça ao pai e ao marido.

Depois de ser colocado o tembeta e do treinamento ao qual são submetidos os rapazes, eles passam a ser considerados kuimba'e, "varão", isto é, já não são mais kyringue, "meninos" nem ñe'ênguchu, adolescentes em processo de mudança. Mas também não atingiram ainda o status de homens, não podem se casar ou participar plenamente das cerimônias religiosas (Larricq 1993).

No caso da mulher, a situação é diferente; finalizado o período de confinamento e das prescrições alimentares, as moças estariam em condições de se casar e de ser mães. Portanto, adquirem o direito de começar a ser parte do grupo das mulheres adultas da aldeia com suas prerrogativas e obrigações.

A "educação", como referida continuamente pelos indígenas quando falavam sobre os conselhos e as advertências que são feitas aos iniciandos, 
está destinada a interiorizar os valores e as normas morais que orientam a vida em sociedade. Assim, o autocontrole que permite aguentar a dor e os incômodos de todo tipo, os jejuns, a completa obediência aos mais velhos e o constante temor das ações dos espíritos que impediriam qualquer tentativa de rebeldia constituem uma constante nos rituais de iniciação de ambos os sexos.

As prescrições alimentares que informam sobre os perigos que existem na interação com as alteridades da floresta, tanto animais e vegetais quanto entes extra-humanos, se repetirão ao longo das suas vidas em situações de passagem, como a gravidez, o nascimento dos filhos, o pós-parto e a síndrome de couvade, entre outros.

Assim como ocorre em outros grupos ameríndios (Vilaça 2002), entre os Mbya a maior parte dos cuidados que devem ser observados nos diferentes períodos da vida é destinada a fixar a alma no corpo, sobretudo nos recém-nascidos e na primeira infância, ou a impedir sua partida mais tarde.

Durante os distintos estados de vulnerabilidade existem restrições na alimentação e se faz necessária a intermediação do líder religioso para que se realize omoatachi, quer dizer, que seja fumegada ritualmente fumaça de tabaco sobre a presa ou os alimentos prontos para consumo, produzindo-se assim a "dessubjetivação xamanística do animal antes de consumi-lo, neutralizando o seu espírito" (Viveiros de Castro 2001) que, caso contrário, poderia buscar vingança na forma de doenças.

Como demonstrado na literatura etnográfica sobre as escolhas de caça e consumo entre os povos amazônicos (Arhem 2001; Carneiro 1970; Descola 1996; Mendes dos Santos 2006; Rival 2001; Zent 2005), a alimentação é regulada por questões culturais, como pode ser visto com clareza no caso dos Mbya, em que o fato de uma espécie ser considerada "impura" ou "proibida" é, para além de outras hipóteses, o resultado da arbitrariedade cultural.

As mulheres, talvez por sua capacidade procriadora, devem observar maiores restrições no consumo de alimentos que poderiam lhes ocasionar futuras doenças relacionadas com a gravidez e o parto. Era frequente os indígenas me explicarem que antigamente as mulheres mbya se "cuidavam" muito. A palavra "cuidar" incluía a dieta seletiva, o uso das pinturas corporais, a utilização de plantas medicinais, as rezas e a conduta específica que deviam ter a respeito de horários e lugares. Os Mbya atribuem muitos dos problemas de saúde que hoje em dia afetam as mulheres ao abandono ou à modificação dessas práticas.

O confinamento das meninas continua a ser realizado nas comunidades, mas os tempos foram encurtados e já não se observam mais todos os preceitos como manda o ritual, salvo naquelas aldeias que ficam em zonas afastadas da floresta. 
O treinamento dos varões ainda é feito com especial ênfase no trabalho coletivo, mas a necessidade de acompanhar os pais nas tarefas agrícolas que se realizam nas propriedades dos brancos, o fato de frequentar a escola e a incorporação de hábitos e atividades diferentes das tradicionais, entre outros fatores, limitam as possibilidades de a iniciação ser realizada de forma completa.

Os rituais de passagem para a maturidade sexual entre os Mbya condensam não apenas as normas que mais tarde vão orientar os papéis que devem desempenhar os adolescentes como homens e mulheres, mas também "educam", como dizem os indígenas, quanto ao modo de se relacionarem com as entidades não humanas. Os "cuidados" que devem ter nesse período de máxima vulnerabilidade serão úteis para as iñengue e para os ñe'ênguchu pelo resto de suas vidas.

Os conselhos dos avós ensinam sobre como ser pessoa e interagir corretamente segundo os cânones da sociedade, mas também sobre como manter a condição de humanos na interação com as alteridades extra-humanas que habitam a floresta.

Recebido em 06 de janeiro de 2014

Aprovado em 10 de novembro de 2014

Tradução de Angela Facundo

Marilyn Cebolla Badie é professora adjunta da Universidad Nacional de Misiones. E-mail: <macebolla@yahoo.com.ar>

\section{Notas}

${ }^{1}$ A docente Petrona González da escola aborígene de Fortín Mbororé obteve esta informação em conversas mantidas em guarani padrão com as mulheres da aldeia a pedido meu.

${ }^{2}$ A etnia Mbya pertence à família linguística tupi-guarani e seus territórios tradicionais compreendem o leste do Paraguai, a província de Misiones, na Argentina, o norte do Uruguai e o sudeste do Brasil até o Oceano Atlântico. 
${ }^{3}$ São conhecidos como Guarani Ñandéva no Brasil e como Chiripá na Argentina, mas se autodenominam Ava Katu Ete.

${ }^{4}$ Recebem o nome de Kaiowá no Brasil, porém, no Paraguai, seu etnônimo é Paî Tavytera.

${ }^{5}$ Sua autodenominação atual é Ava-Guarani.

${ }^{6}$ Este dado foi corroborado ao observar uma das escassas fotografias existentes sobre os Mbya na primeira metade do século XX. Trata-se de uma fotografia de pequeno tamanho na qual aparece uma moça vestida da maneira tradicional, levando um cesto ajaka sobre suas costas e nos tornozelos podem ser vistas as cordinhas do tetymakuaa (Sosa 1928).

${ }^{7}$ Kaiowá ou Paî Tavytera, Chiripá ou Guarani Ñandéva Embya.

${ }^{8}$ Denominação que recebem os brancos.

${ }^{9}$ Os indígenas traduzem este termo para o espanhol como "señora" ou "mujer de respeto".

10 Polenta de milho.

${ }^{11}$ Farelo de milho branco.

${ }^{12}$ Pão de milho cozido nas cinzas.

${ }^{13}$ Mingau de milho.

${ }^{14}$ Denominação do fruto da palma pindo.

${ }^{15}$ Atualmente, nomeia-se o consumo das duas espécies de tamanduás referindo-se a práticas do passado; a espécie de maior tamanho encontra-se quase extinta em Misiones e a pequena está em situação vulnerável devido à caça esportiva e ao desmatamento.

${ }^{16}$ Normalmente nos hortos ou na floresta circundante.

${ }^{17} \mathrm{Na}$ visão mbya, o ñe'ê, "palavra-alma", é a alma principal enviada pelas divindades, a que concentra a essência da pessoa. Mas também existe uma segunda alma, ãngue, que se desenvolve a partir do nascimento e que acumula os erros e as transgressões ao longo da vida (Cebolla Badie 2013).

${ }^{18}$ Nosso pai verdadeiro.

${ }^{19}$ Cortar as ervas daninhas com o machado, faca longa de aproximadamente 50 a $60 \mathrm{~cm}$ de comprimento. 
${ }^{20}$ Assentamento. No passado, um tekoa constituía o território de caça, pesca, colheita e horticultura de uma patrilinhagem.

${ }^{21}$ Em finais de 2012, na aldeia de Takuapi, observei com surpresa que alguns adolescentes exibiam o tembe kuaa, que consiste em um pedacinho de cana. Quando perguntei ao cacique sobre o motivo desse repentino retorno do ritual que tinha sido abandonado há muito tempo atrás, ele respondeu que precisavam frisar o "ser mbya" e que talvez desse jeito eles conseguissem ter um maior controle sobre os jovens, que estavam muito interessados em viver como os brancos.

${ }^{22}$ De todas essas tarefas, fiar o tecido no tear, a confecção das cordinhas de cabelo e a fabricação dos arcos e das flechas praticamente desapareceram.

\section{Referências bibliográficas}

AMBROSETTI, Juan Bautista. 1898. "Los indios Cainguá del Alto Paraná (Misiones)". Boletín del Instituto Geográfico Argentino, XV:661-744.

ÅRHEM, Kaj. 2001. "La red cósmica de la alimentación. La interconexión de humanos y naturaleza en el noroeste de la Amazonia". In: Philippe Descola \& Gísli Pálsson (eds.), Naturaleza y sociedad. Perspectivas antropológicas. México: Siglo XXI. pp. 214-236.

CADOGAN, León. 1992a. Ayvu Rapyta. Textos míticos de los Mbya-Guaraníes del Guairá. Biblioteca Paraguaya de Antropología, XVI. Asunción: Ceaduc/Cepag. - 1992b. Diccionario Mbya Guaraní Castellano. Biblioteca Paraguaya de Antropología, XVII. Asunción: Ceaduc/ Cepag.

CARNEIRO, Robert. 1970. "Hunting and hunting magic among the Amahuaca of the Peruvian Montaña". Ethnology, 9(4):331-341.

CEBOlla BADIE, Marilyn. 2000. “El conocimiento mbya-guaraní de las aves. Nomenclatura y Clasificación". Suplemento Antropológico, XXXV(2):9-188.

- 2009. Etnografía sobre la miel en la cultura mbya-guaraní. Quito: Abya Yala.

- 2013. Cosmología y naturaleza mbya-guaraní. Tesis de Doctorado, Departamento de Antropología Social e Historia de América y África, Universidad de Barcelona.

CHASE SARDI, Miguel. 1992. El precio de la sangre. Tuguy Nêe Repy. Biblioteca Paraguaya de Antropología, XIV. Asunción: Ceaduc/Cepag.

CITRO, Silvia. 2008. "Creando una mujer". In: S. Hirsch (org.), Mujeres indígenas en la Argentina. Cuerpo, trabajo y poder. Buenos Aires: Editorial Biblos. pp. 12-36.

DESCOLA, Philippe. 1996. La selva culta. Simbología y praxis en la ecología de los achuar. Quito: Abya Yala.

FAUSTO, Carlos. 2005. "Se deus fosse jaguar: canibalismo e cristianismo 
entre os Guarani (séculos XVI-XX)". Mana. Estudos de Antropologia Social, 11(2):385-418.

GOW, Peter. 2001. An Amazonian myth and its history. Oxford: Oxford University Press.

HIRSCH, Silvia. 2008. "Maternidad, trabajo y poder: cambios generacionales en las mujeres guaraníes del norte argentino". In: S. Hirsch (org.), Mujeres indígenas en la Argentina. Cuerpo, trabajo y poder. Buenos Aires: Editorial Biblos. pp. 231-253.

LARRICQ, Marcelo. 1993. Ipytûma. Construcción de la persona entre los Mbya-Guaraní. Posadas: Editorial Universitaria-UNaM.

LÉVI-STRAUSS, Claude. 2005. Mitológicas II. De la miel a las cenizas. México: Fondo de Cultura Económica.

MAYNTZHUSEN, Federico. 2009. Los Aché Guayakí. Posadas: Junta de Estudios Históricos de Misiones.

MENDES DOS SANTOS, Gilton. 2006. Da cultura à natureza. Um estudo do cosmos e da ecologia dos Enawene-Nawe. Tese de Doutorado, Universidade de São Paulo.

MÜLLER, Franz. 1989. Etnografía de los Guaraní del Alto Paraná. Buenos Aires: Centro Argentino de Etnología Americana.

RIVAL, Laura. 2001. "Cerbatanas y lanzas. La significación social de las elecciones tecnológicas de los huaorani". In: Gisli Palsson \& Philippe Descola (org.), Naturaleza y sociedad. Perspectivas antropológicas. México: Siglo XXI. pp. 169-192. SCHADEN, Egon. 1974. Aspectos fundamentais de cultura guarani. São Paulo: Editora da Universidade de São Paulo.

SCHUSTER, Adolf. 1929. Paraguay, Land, Volk, Geschichte, Wirtschaftsleben und Kolonisation. Stuttgart: Strecker und Schröder.
SOSA, Atanasio 1928. Guía general de Misiones para 1928-1929. Posadas: A Soda.

TURNER, Victor. 1980. La selva de los símbolos. Madrid: Siglo XXI.

VILAÇA, Aparecida. 2002. "Making kin out of others in Amazonia". The Journal of the Royal Anthropological Institute, 8(2):347-365.

VIVEIROS DE CASTRO, Eduardo. 2011. A inconstância da alma selvagem e outros ensaios de antropologia. São Paulo: Cosac y Naify. . 2007. "A floresta de cristal: notas sobre a ontologia dos espíritos amazônicos". Cadernos de campo, 14-15:319-338. -1992. From the enemy point of view. Humanity and divinity in an Amazonian society. Chicago: The University of Chicago Press.

ZENT, Eglée. 2005. "The hunter-self: perforations, prescriptions and primordial beings among the Hotï, Venezuelan Guayana". Tipitu, 3(1):34-76. 


\section{Resumo}

No presente artigo indago a respeito dos rituais de iniciação entre os Mbya-Guarani em Misiones, Argentina. A puberdade parece ser uma das etapas mais críticas e perigosas do ciclo vital mbya. A alma da pessoa encontra-se num estado de grande vulnerabilidade e pode ser presa das alteridades extra-humanas da floresta. Por isto, devem se apurar os cuidados que incluem restrições alimentares e um forte controle do comportamento. A principal característica do ritual para as meninas é a reclusão a que são submetidas; os meninos, pelo contrário, são expostos a constantes atividades e serviços que podem ser considerados públicos. As iñengue e os ñe'enguchu devem aprender a se comportar segundo os modelos feminino e masculino da sociedade mbya, já que as mudanças não envolvem somente o corpo, mas também o status que terão dali em diante.

Palavras-chave Rituais de puberdade, Relação natureza-cultura, Alteridades extra-humanas, Etnia Mbya-Guarani.

\section{Abstract}

This article studies the initiation rituals of the mbya-Guarani in Missiones, Argentina. Puberty seems to be the most critical and dangerous time in the mbya life cycle. A person's soul is in a state of great vulnerability and can become prey to extra-human alterities of the forest. It is thus necessary to be extra careful, which includes adopting alimentary restrictions and maintaining tight control of one's behaviour. The main characteristic of the girl's ritual is the seclusion to which they are submitted, while boys, in contrast, are exposed to constant activities and public life. The iñengue and the ñe'enguchu must learn to behave according to the feminine and masculine models of mbya society, because the changes involve not only their bodies, but also the status that they will henceforth assume.

Key words Puberty rituals, Natureculture relations, Extra-human alterities, Mbya-Guaraní ethnic group. 